\title{
Growth in Cartilage-Hair Hypoplasia
}

\author{
OUTI MÄKITIE, JAAKKO PERHEENTUPA, AND ILKKA KAITILA
}

Department of Medical Genetics and Children's Hospital, University of Helsinki, Helsinki, Finland

\begin{abstract}
Cartilage-hair hypoplasia is an osteochondrodysplasia with short-limbed short stature. The cartilage-hair hypoplasia gene is exceptionally prevalent in Finland; more than 100 patients have been identified. We have analyzed the growth of 100 Finnish patients and present cartilage-hair hypoplasia-specific growth charts of height and weight for height. The disproportions were analyzed by sitting height, subischial leg height, sitting height:height ratio, and span-height difference. The stature was short at birth with a mean relative length of $-3.0 \mathrm{SD}$. The median adult height was $131.1 \mathrm{~cm}(-7.9 \mathrm{SD}$, range 110.7 to $149.0 \mathrm{~cm})$ for 15 males and $122.5 \mathrm{~cm}(-7.9 \mathrm{SD}$, range 103.7 to $137.4 \mathrm{~cm}$ ) for 20 females. The progression of the growth failure was partly explained by weakness or absence of pubertal growth spurt. Weight for height was above normal median in childhood and increased further at puberty. Most of the adults were overweight. The adults' mean relative head circumference was -0.9 SD. Growth was disturbed both in the limbs and in the spine, more severely in the limbs. Adult height showed no correlation with the midparent height. The charts are useful for assessment of growth, prediction of adult height, detection of superimposed disorders, and evaluation of growth-accelerating therapy. (Pediatr Res 31: 176-180, 1992)
\end{abstract}

\section{Abbreviations}

CHH, cartilage-hair hypoplasia

$\mathrm{CHH}$ is an autosomal recessive osteochondrodysplasia with short-limbed short stature (1). It is distinguished by clinical and radiographic characteristics and association of defective cellmediated immunity (2-5). The basic defect and the pathophysiology of the growth failure are unknown. The prevalence of the $\mathrm{CHH}$ gene is exceptionally high in the Finns (6), with $>100$ recognized patients in a population of 5.0 million.

As a part of a multidimensional evaluation of $\mathrm{CHH}$, we have studied the growth and its correlates in 100 patients and present $\mathrm{CHH}$-specific growth charts for height and weight for height.

\section{MATERIAL AND METHODS}

The study was based on an extended follow-up of 65 Finnish patients and on growth data of 35 additional patients. There were 56 females and 44 males in a total of 81 families; 17 families included two or three affected siblings.

The diagnosis was based on rhizomelic short-limbed short stature, generalized laxity of joint ligaments, metaphyseal flaring

Received April 18, 1991; accepted September 22, 1991.

Correspondence and reprint requests: Outi Mäkitie, M.D., Helsinki University Hospital, Department of Medical Genetics, Tukholmankatu 8 F, SF-00290 Helsinki, Finland.

Supported by grants from the University of Helsinki, the Finnish Medical Foundation, the Paulo Foundation, and the Päivikki and Sakari Sohlberg Foundation, Helsinki, Finland. and irregularities of the growth plates in childhood radiographs, and compatible genealogy. Hair hypoplasia was used only as a positive criteria; normal hair does not rule out $\mathrm{CHH}$. In some families one affected sibling had hypoplastic hair and another had normal hair. Eight patients had normal hair. Growth data were collected from birth records, child health centers, schools, and hospitals. Parental heights were obtained by measurement or from records. Four males and four females had been treated with growth-promoting hormones; only pretherapy data were accepted from them.

At the visits, supine total and crown-rump length were measured in patients up to $2 \mathrm{y}$ of age and height and sitting height were measured in older patients, with Harpenden instruments (Holtain Limited, UK) to the nearest mm. Weight in thin underwear was measured with standard scales. The largest occipitofrontal head circumference was measured with a thin metal tape. Span was measured across the front as the greatest distance between the fingertips with the arms stretched out horizontally.

Thirteen patients were born before $38 \mathrm{wk}$ gestation. Their term size was extrapolated using Finnish standards of prenatal growth (7), and age was calculated from term. Individual growth curves were drawn using all available data. They were smoothed by eye and read at the exact ages of $0.25,0.5,0.75,1.0$, and $1.5 \mathrm{y}$ and, thereafter, at each full year up to the age of 20 . The interpolation was performed only over measurement intervals $\leq 6$ mo during the first $2 \mathrm{y}$ and $\leq 1.5 \mathrm{y}$ thereafter. For adults, only measurements at $\geq 20$ y were accepted. The data were then pooled for each sex, and 10 th, 25th, 50th, 75th, and 90th percentile values were calculated at each age of interpolation. The distributions of heights were skewed to the left. Therefore, percentiles were calculated instead of SD. The percentile curves were smoothed by eye. They were compared with the Finnish norms (8). For longitudinal analysis, the median and range of individual changes in relative height (deviation of height, in SD units, from mean height for age and sex) were calculated from birth to $1 \mathrm{y}$ and from $10 \mathrm{y}$ to adulthood. The weights were interpolated at exact heights at $5-\mathrm{cm}$ intervals starting at $60 \mathrm{~cm}$. The $25 \mathrm{th}, 50 \mathrm{th}$, and 75 th percentile values at each height were plotted on the Finnish growth charts (8) to obtain relative weights [deviation of weight, in $\%$, from median weight for height (length at ages $<2.0 \mathrm{y}$ ) and sex; for birth weight, deviation from the mean value for sex, in SD units]. Adult weights were analyzed as body mass index (weight-square of height ratio) and compared with the Finnish norms for age and sex (9).

The individual values of relative head circumference (deviation of head circumference, in SD units, from the mean value for age and sex) (10) were pooled, males and females together, at the ages of $0.5,1.5$, and 3.0 y and, thereafter, at every second full year, and 25 th, 50 th, and 75 th percentile values at each age were calculated. The percentile curves were smoothed by eye.

The pubertal growth was analyzed by comparing the individual growth curves with the Infancy Childhood Puberty (ICP) standards of Karlberg et al. (11); these divide growth into the three additive components of infancy, childhood, and puberty, which can be assessed separately. The height spurt was considered normal if there was $\geq 1.0 \mathrm{SD}$ increase in relative height from the childhood standards. If the increase was $\geq 0.3 \mathrm{SD}$ but $<1.0 \mathrm{SD}$, 
the spurt was considered weak, and if the increase was $<0.3 \mathrm{SD}$, the spurt was considered absent.

Disproportions were determined by comparing with norms $(12,13)$ the sitting height, standing subischial leg height (height - sitting height), sitting height-height ratio (sitting height \%), and span-height difference.

For correlation studies, the relative lengths/heights at birth, $1.0 \mathrm{y}$, and $5.0 \mathrm{y}$ were compared with the relative adult height SD score. Because the relative height usually remained stable at 4.0 $6.0 \mathrm{y}$ (Fig. 1), the relative height at 4.0 or $6.0 \mathrm{y}$, or their mean, was used when the 5.0 y height was not known.

Simple linear regression was used for statistical analysis. The study was approved by the ethical committee of the Children's Hospital.

\section{RESULTS}

Length/height. At birth, the mean relative length was - 2.9 SD for boys and $-3.0 \mathrm{SD}$ for girls, indicating prenatal onset of the growth disturbance (Table 1). The growth failure was progressive; there was a rapid decrease in relative length/height during the 1 st y (median decrease 2.1 SD, range 0.2 to $5.3 \mathrm{SD}, n=56$ ) and another decrease at pubertal age (median $2.3 \mathrm{SD}$, range 0.1 to 3.0 SD, $n=14$ ) (Fig. 1). The median adult height was $131.1 \mathrm{~cm}$ $(-7.9 \mathrm{SD}$, range 110.7 to $149.0 \mathrm{~cm}$ ) for 15 males and $122.5 \mathrm{~cm}$ $(-7.9 \mathrm{SD}$, range 103.7 to $137.4 \mathrm{~cm}$ ) for 20 females (Fig. 2, Table 2).

Weight. At birth, the mean relative weight was $-0.8 \mathrm{SD}$ for boys and -0.9 for girls (Table 1). In childhood, most of the patients were clearly heavier than average normal children of the same height (8). Around puberty, relative weight increased further (Fig. 3). The median adult weight was $54.5 \mathrm{~kg}$ (range 40.5 to $90.0 \mathrm{~kg}$ ) for 13 males, and $44.3 \mathrm{~kg}(32.0$ to $58.5 \mathrm{~kg})$ for 20 females (Table 2). Seven of the 11 adult males and 12 of the 18 adult females had body mass index over the 95 th percentile for

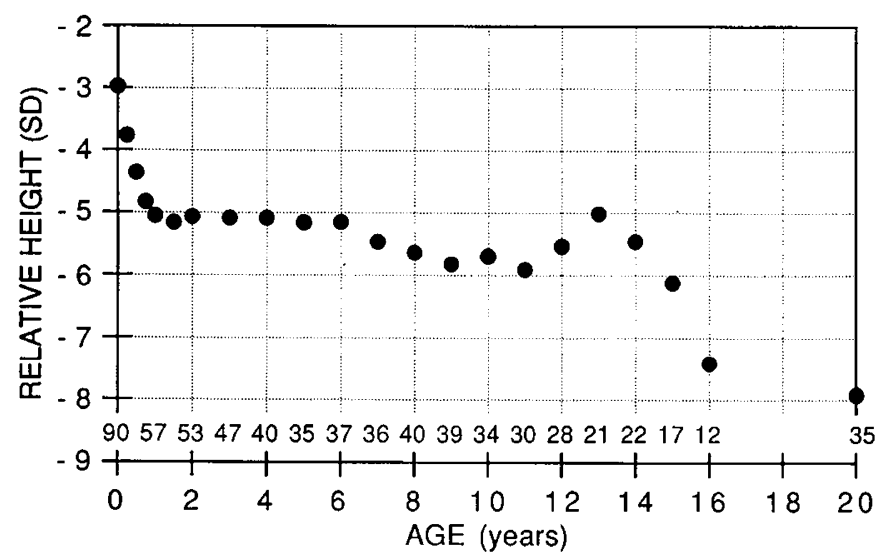

Fig. 1. Median relative height $v s$ age (male and female patients together). Number of patients at each age is given.

Table 1. Size at birth (means and ranges of absolute and relative values)

\begin{tabular}{lccc}
\hline & Mean & SD & $n$ \\
\hline Length (cm) & & & \\
$\quad$ Males & $45.8(38.0-50.0)$ & $-2.9(-7.3--0.6)$ & 41 \\
$\quad$ Females & $44.9(38.0-51.0)$ & $-3.0(-7.0-+0.5)$ & 50 \\
Weight (g) & & & \\
$\quad$ Males & $3360(2460-4230)$ & $-0.8(-2.7-+1.1)$ & 42 \\
Females & $3200(1920-4040)$ & $-0.9(-3.7-+1.0)$ & 51 \\
Head circum- & & & \\
$\quad$ ference (cm) & & & \\
Males & $35.7(33.0-38.5)$ & $+0.2(-1.9-+2.3)$ & 23 \\
Females & $34.4(32.0-36.5)$ & $-0.5(-2.4-+1.1)$ & 24 \\
\hline
\end{tabular}
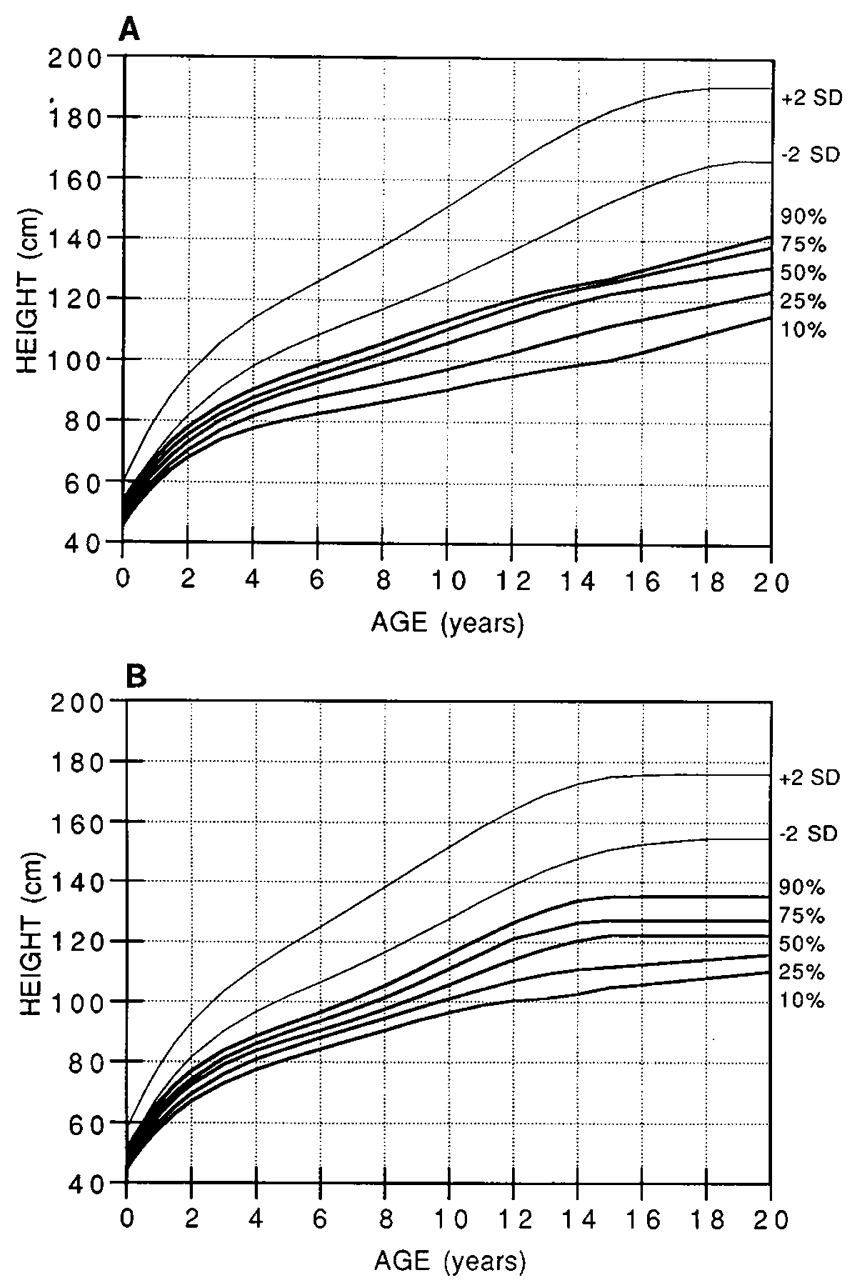

Fig. 2. Percentiles (10th, 25th, 50th, 75th, and 90th) of height $v s$ age for male (A) and female (B) patients, with (mean $\pm 2 \mathrm{SD}$ ) range of normal population.

age and sex. The mean body mass index was 33.8 and $30.5 \mathrm{~kg} /$ $\mathrm{m}^{2}$ for these males and females, respectively.

Head circumference. At birth, the median relative head circumference was close to $0 \mathrm{SD}$ (Table 1). It then decreased to -1.0 SD by the age of $2.0 \mathrm{y}$ and decreased further to $-1.3 \mathrm{SD}$ by 6.0 to $12.0 \mathrm{y}$. The median adult value was $-0.9 \mathrm{SD}$ (range -3.8 to $+2.0 \mathrm{SD}, n=24$ ).

Puberty. The mean age at menarche was 13 y $(n=15)$. This, as well as notes on breast and genital development, is consistent with normal pubertal maturation (14). Hair hypoplasia invalidated pubic hair as a puberty indicator. There were 16 male and 18 female patients with a sufficient number of height measurements in the years of puberty. Height spurt appeared normal in only two males and one female. It was absent in two males and five females, and weak in all others.

Disproportion of stature. The trunk was long in relation to the short lower limbs. This disproportion increased with age (Fig. 4). The trunk height was also markedly affected (Fig. 4). The median adult relative values (deviation from the mean value for age and sex, in SD units) were $-7.3 \mathrm{SD}$ (range -10.2 to $-5.6 \mathrm{SD}$ ) for subischial leg height and $-4.4 \mathrm{SD}(-7.3$ to $-1.7 \mathrm{SD})$ for sitting height. The more severe the growth failure, the greater was the disproportion (Fig. 5). The mean span-height difference was normal at all ages. The mean adult span-height difference was $2.2 \mathrm{~cm}$ for males $(n=8)$ and $1.9 \mathrm{~cm}$ for females $(n=16)$. Obviously, this difference is not an accurate indicator of the growth failure of the upper limbs. In absence of better measurements, we can only conclude that the disorder affected similarly the growth of the upper limbs and the total height. This suggests 
Table 2. Percentiles of height, weight, and sitting height of male and female patients at different ages

\begin{tabular}{|c|c|c|c|c|c|c|c|c|c|c|c|c|}
\hline \multirow[b]{2}{*}{ Age (y) } & \multicolumn{4}{|c|}{ Height $(\mathrm{cm})$} & \multicolumn{4}{|c|}{ Weight $(\mathrm{kg})$} & \multicolumn{4}{|c|}{ Sitting height $(\mathrm{cm})$} \\
\hline & $10 \%$ & $50 \%$ & $90 \%$ & $n$ & $10 \%$ & $50 \%$ & $90 \%$ & $n$ & $10 \%$ & $50 \%$ & $90 \%$ & $n$ \\
\hline \multicolumn{13}{|l|}{ Males } \\
\hline 0 & 42.0 & 46.0 & 49.0 & 41 & 2.8 & 3.4 & 4.0 & 42 & & & & \\
\hline 1.0 & 60.8 & 64.2 & 69.1 & 27 & 7.0 & 8.1 & 9.2 & 27 & 42.0 & 44.4 & 47.6 & 10 \\
\hline 2.0 & 68.0 & 72.8 & 77.6 & 28 & 9.3 & 10.3 & 11.7 & 28 & 46.4 & 48.3 & 51.3 & 11 \\
\hline 3.0 & 72.6 & 79.7 & 83.2 & 22 & 10.1 & 12.1 & 13.2 & 23 & 50.4 & 52.5 & 55.4 & 6 \\
\hline 4.0 & 76.2 & 83.9 & 87.8 & 18 & 11.2 & 12.9 & 14.3 & 18 & 50.9 & 52.9 & 56.2 & 9 \\
\hline 5.0 & 78.6 & 87.6 & 94.0 & 16 & 11.5 & 14.6 & 18.2 & 16 & 53.6 & 55.6 & 56.8 & 7 \\
\hline 6.0 & 82.1 & 92.8 & 96.9 & 18 & 12.5 & 16.2 & 18.9 & 18 & 55.2 & 57.2 & 59.7 & 7 \\
\hline 7.0 & 85.7 & 96.4 & 105.4 & 16 & 14.7 & 17.8 & 22.9 & 15 & 56.2 & 59.6 & 66.6 & 5 \\
\hline 8.0 & 87.8 & 100.7 & 108.6 & 21 & 14.7 & 18.8 & 26.4 & 21 & 55.9 & 61.5 & 64.9 & 5 \\
\hline 9.0 & 89.3 & 103.9 & 110.0 & 22 & 14.7 & 20.3 & 27.7 & 21 & 57.2 & 63.0 & 68.3 & 10 \\
\hline 10.0 & 90.8 & 106.8 & 112.0 & 19 & 15.4 & 22.0 & 28.4 & 20 & 56.7 & 60.1 & 66.4 & 11 \\
\hline 11.0 & 92.4 & 107.1 & 114.5 & 14 & 15.5 & 23.2 & 28.9 & 15 & & 66.4 & & 4 \\
\hline 12.0 & 94.0 & 111.8 & 118.7 & 13 & 17.2 & 25.2 & 35.4 & 13 & & 68.1 & & 4 \\
\hline 13.0 & 94.7 & 115.9 & 122.5 & 10 & 18.1 & 31.6 & 42.4 & 8 & & 68.6 & & 3 \\
\hline 14.0 & 98.9 & 119.8 & 125.5 & 10 & 20.6 & 34.7 & 40.5 & 7 & 71.6 & 73.2 & 78.1 & 5 \\
\hline 15.0 & 101.8 & 122.9 & 131.5 & 8 & 23.5 & 36.5 & 46.2 & 7 & 72.0 & 75.0 & 78.2 & 5 \\
\hline 20.0 & 115.0 & 131.1 & 142.0 & 15 & 43.1 & 54.5 & 74.8 & 13 & 73.7 & 80.5 & 85.2 & 7 \\
\hline \multicolumn{13}{|l|}{ Females } \\
\hline 0 & 43.4 & 45.0 & 47.0 & 49 & 2.7 & 3.2 & 3.9 & 51 & & & & \\
\hline 1.0 & 57.8 & 64.2 & 67.4 & 30 & 6.4 & 7.6 & 8.8 & 30 & 40.8 & 42.4 & 46.2 & 14 \\
\hline 2.0 & 66.0 & 71.8 & 75.6 & 25 & 8.3 & 9.7 & 10.8 & 25 & 44.4 & 46.9 & 49.6 & 8 \\
\hline 3.0 & 71.8 & 77.5 & 81.9 & 25 & 9.1 & 11.4 & 12.2 & 25 & 44.8 & 48.2 & 51.6 & 6 \\
\hline 4.0 & 76.1 & 82.9 & 87.8 & 22 & 9.8 & 12.8 & 13.5 & 21 & 47.3 & 49.6 & 52.9 & 7 \\
\hline 5.0 & 81.7 & 87.1 & 92.9 & 19 & 10.8 & 14.3 & 15.4 & 18 & 50.3 & 52.5 & 56.9 & 9 \\
\hline 6.0 & 83.9 & 91.7 & 97.5 & 19 & 12.0 & 15.4 & 16.5 & 19 & & 54.0 & & 2 \\
\hline 7.0 & 87.7 & 94.6 & 102.5 & 20 & 13.4 & 17.0 & 17.5 & 20 & 53.8 & 55.4 & 60.6 & 5 \\
\hline 8.0 & 90.9 & 98.2 & 104.5 & 19 & 14.8 & 18.2 & 19.6 & 19 & 57.2 & 58.8 & 60.7 & 6 \\
\hline 9.0 & 94.5 & 101.2 & 109.0 & 17 & 15.7 & 20.5 & 23.2 & 15 & 58.6 & 59.7 & 62.4 & 6 \\
\hline 10.0 & 96.8 & 104.8 & 115.5 & 15 & 18.8 & 22.5 & 26.4 & 14 & & 62.2 & & 4 \\
\hline 11.0 & 98.6 & 108.3 & 121.4 & 16 & 18.2 & 24.6 & 30.3 & 14 & 59.7 & 64.2 & 67.7 & 7 \\
\hline 12.0 & 98.5 & 112.7 & 126.7 & 15 & 20.2 & 26.9 & 34.7 & 14 & 61.5 & 67.9 & 72.8 & 6 \\
\hline 13.0 & 98.3 & 120.0 & 130.9 & 11 & 22.5 & 30.1 & 39.5 & 10 & 62.5 & 63.9 & 74.5 & 5 \\
\hline 14.0 & 103.1 & 121.5 & 133.5 & 12 & 25.0 & 34.7 & 42.3 & 11 & & 68.7 & & 4 \\
\hline 15.0 & 103.1 & 120.8 & 135.0 & 9 & 28.7 & 41.3 & 46.1 & 9 & & 73.9 & & 3 \\
\hline 20.0 & 110.3 & 122.5 & 135.4 & 20 & 35.8 & 44.3 & 56.0 & 20 & 69.2 & 75.0 & 81.0 & 17 \\
\hline
\end{tabular}

that the growth failure was more severe in the lower than the upper limbs.

Correlates of adult height. The adult relative height could be compared with the midparent relative height in 15 male and 20 female patients. No significant correlation was present $(r=0.29$, $p>0.1)$; the results were similar for both sexes separately. Coefficient of correlation with relative adult height was, for relative length at birth, $r=0.53(p<0.01, n=35)$; for relative height at $1.0 \mathrm{y}, r=0.68(p<0.05, n=11)$; and, for relative height at $5.0 \mathrm{y}, r=0.69(p<0.05, n=11)$. The relative height was on average $2.7 \mathrm{SD}$ greater at $5.0 \mathrm{y}$ than in adulthood.

\section{DISCUSSION}

$\mathrm{CHH}$, a metaphyseal chondrodysplasia, interferes profoundly with normal growth. All metaphyses are affected, most severely those of the knees and ankles (15). Because the growth of the vertebrae is less severely disturbed, the result is short-limbed disproportionate short stature (1). The severity of growth disturbance, as well as other clinical features, varies greatly $(1,3)$. We know no previous studies of growth in $\mathrm{CHH}$. Heights of adult Amish patients varied from 42 to 58 inches (107 to 147 cm) (1), in accord with the range of 103.7 to $149.0 \mathrm{~cm}$ in the Finnish patients. An abnormally high upper segment-lower segment ratio was observed in the Amish patients but was not evaluated further (1).

The relative height of the patients decreased during the 1st y and puberty (Fig. 1). The cause and pathophysiology of the first deviation are unclear. The pubertal decrease is caused by the absence or weakness of the growth spurt.

Final height did not correlate with midparental height. It is determined more by the severity of the metaphyseal dysplasia than by the normal genetic factors. This is also our clinical impression: the degree of the growth disturbance varies greatly even among siblings. Because final height is a major concern of the parents, a reliable method of prediction would be valuable. However, the progressive nature of the growth failure invalidates the common methods of adult height prediction.

Disease-specific growth standards exist for females and males with achondroplasia (16), based on cross-sectional and longitudinal growth data of 403 patients. Their height standards resemble those of our $\mathrm{CHH}$ patients, and the final heights are approximately equal. In contrast, for head circumference the curves run on different sides of the normal median: the mean relative head circumference is +3 SD for achondroplastic patients and -1 SD for $\mathrm{CHH}$ patients. There is, however, some overlap because of great variation in both disorders. The disproportion of the achondroplastic stature was analyzed by the ratio of upper and lower segments and, therefore, the results are not quite comparable with ours. In achondroplasia the relative upper segment height was close to normal in childhood, but in adult males it was -2 $\mathrm{SD}$ and in adult females, $-3 \mathrm{SD}$. The lower segment was profoundly disturbed in growth, being in adults approximately -11 $\mathrm{SD}$. In $\mathrm{CHH}$, as compared with achondroplasia, growth deficiency was more severe (median -4.4 SD in adults) for the vertebrae and less severe (median $-7.3 \mathrm{SD}$ in adults) for the 

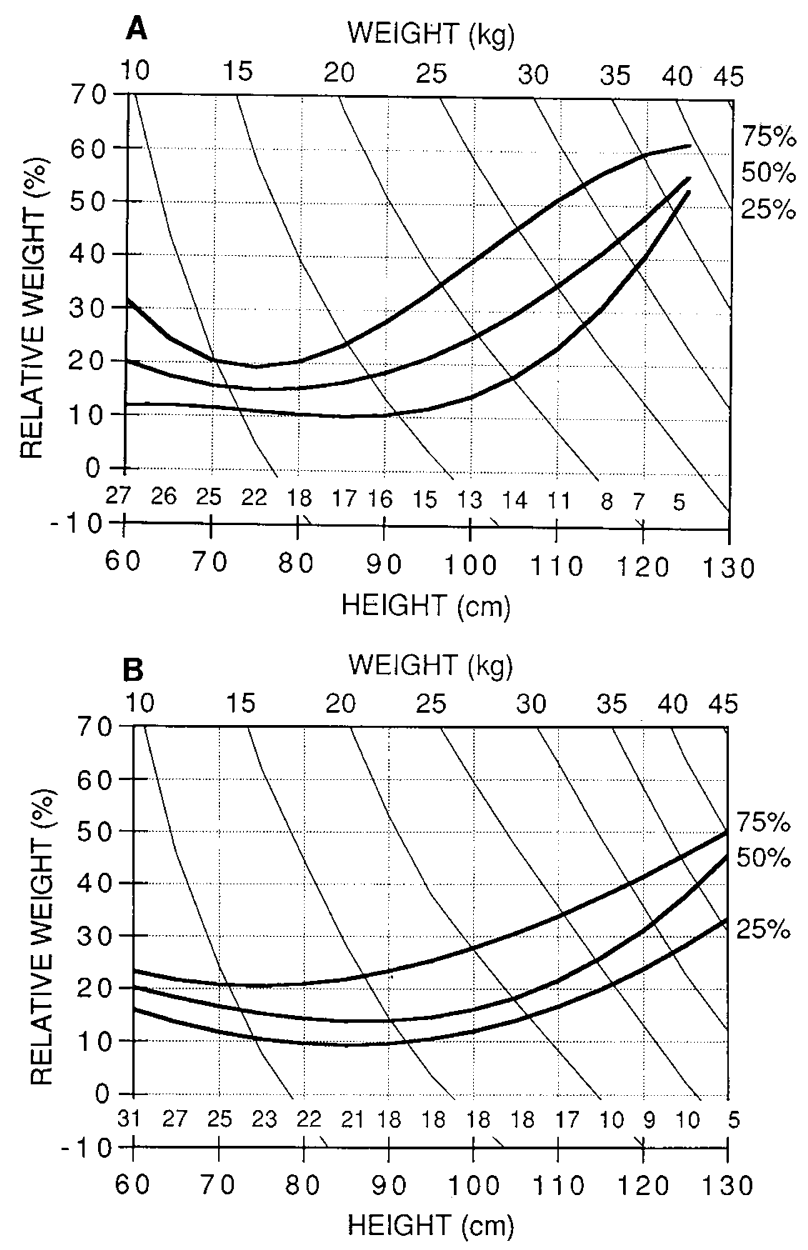

Fig. 3. Relative weight $v s$ height for male (A) and female (B) patients on standard chart of weight for height. The horizontal 0 line indicates median for normal children. Number of patients at each height is given.

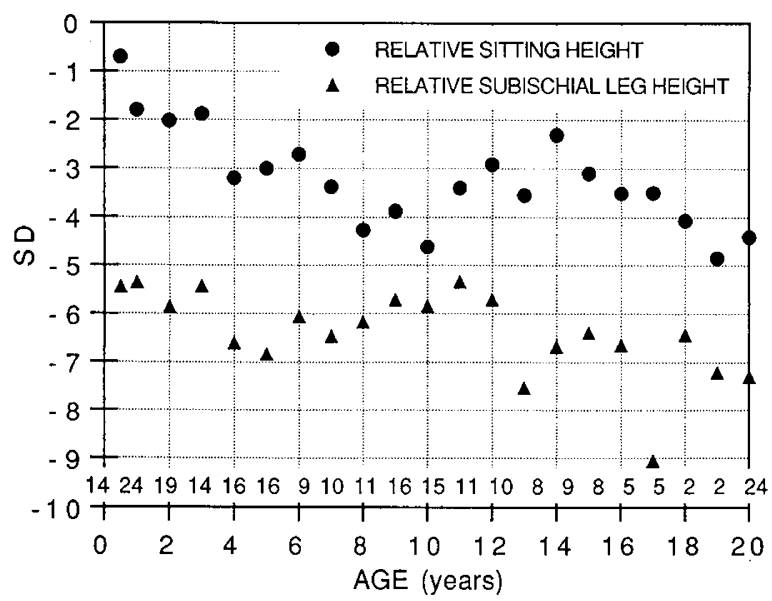

Fig. 4. Median values of relative sitting height and subischial leg height $v s$ age (male and female patients together). Number of patients at each age is given.

lower limbs (Fig. 4). Thus, the disproportion is less severe in $\mathrm{CHH}$ than in achondroplasia.

Height standards have also been published for diastrophic dysplasia, spondyloepiphyseal dysplasia congenita, and pseudoachondroplasia (17). They are based on relatively small numbers of patients, with longitudinal measurements in only a few patients and male and female measurements combined. These growth disorders are more severe than $\mathrm{CHH}$ : the mean adult height for diastrophic dysplasia was $118.3 \mathrm{~cm}(n=21)$; for

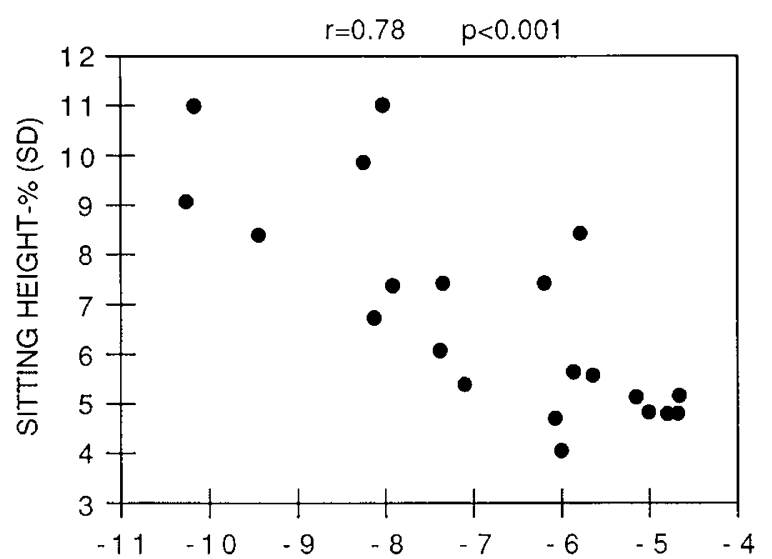

DEVIATION FROM THE NORMAL EXPECTED ADULT HEIGHT (SD)

Fig. 5. Relative sitting height $\%$ vs the severity of growth failure in adult patients $(n=21)$. Severity is given as deviation from height expected for midparent height.

spondyloepiphyseal dysplasia congenita, $115.5 \mathrm{~cm}(n=18)$; and for pseudoachondroplasia, $118.8 \mathrm{~cm}(n=30)$. Pseudoachondroplasia differed from the others by divergence from normal growth only after the age of $2.0 \mathrm{y}$.

A tendency toward overweight may be associated with osteochondrodysplasias. In achondroplasia, the prevalence of obesity was reported to be between 13 and $43 \%$, according to body mass index and triceps skinfold (18). In our series, most of the children had relative weight above the normal mean, with a median of $>30 \%$ at heights $>105 \mathrm{~cm}$, and $>60 \%$ of the adults had a body mass index over the 95th percentile. Evaluation of these results is problematic. According to a recent Finnish study (8), median weights for height are similar in pubertal and prepubertal children. This is, however, in conflict with Dutch norms (19). Because the standards of weight for heights $<120 \mathrm{~cm}$ are based on measurements of prepubertal children, they might overestimate the prevalence of overweight in $\mathrm{CHH}$, inasmuch as the major increase in relative weight coincided with puberty. In addition, $\mathrm{CHH}$ seems to lead to a true relative overweight of the skeleton. This may invalidate body mass index in estimation of overweight. Skinfold thickness measurements are needed to settle the prevalence of overweight. Nevertheless, most of our adult patients were clinically obese.

The growth charts presented should prove useful in predicting adult height and assessing "normality" of growth in CHH patients. Measurements largely diverging from the standards may indicate a superimposed disorder, such as intestinal malabsorption or severe immunodeficiency, both occasionally associated with $\mathrm{CHH}$. Furthermore, no growth promoting medication or surgical procedures can be evaluated without knowledge of the natural growth in the disorder. Adult height prediction will be valued by the parents and the prepubertal patients and will give them more time to adapt to the short stature in adulthood.

\section{REFERENCES}

1. McKusick VA, Eldrige R, Hostetler JA, Ruangwit U, Egeland JA 1965 Dwarfism in the Amish II. Cartilage-hair hypoplasia. Bull Johns Hopkins Hosp 116:285-326

2. Lux SE, Johnston RB, August CS, Say B, Penchaszadeh VB, Rosen FS, McKusick VA 1970 Chronic neutropenia and abnormal cellular immunity in cartilage-hair hypoplasia. N Engl J Med 282:231-236

3. Virolainen M, Savilahti E, Kaitila I, Perheentupa J 1978 Cellular and humoral immunity in cartilage-hair hypoplasia. Pediatr Res 12:961-966

4. Ranki A, Perheentupa J, Andersson LC, Häyry P 1978 In vitro T- and B-cell reactivity in cartilage hair hypoplasia. Clin Exp Immunol 32:352-360

5. Polmar SH, Pierce GF 1986 Cartilage hair hypoplasia: immunological aspects and their clinical implications. Clin Immunol Immunopathol 40:87-93

6. Kaitila I, Perheentupa J 1980 Cartilage-hair hypoplasia. In: Eriksson AW, Forsius H, Nevanlinna HR, Workman PL, Norio RK (eds) Population Structure and Genetic Disorders. Academic Press, London, pp 588-591

7. Pihkala J, Hakala T, Voutilainen P, Raivio K 1989 Uudet suomalaiset sikiön kasvukäyrät [In Finnish]. Duodecim 105:1540-1546 
8. Sorva R, Lankinen S, Tolppanen EM, Perheentupa J 1990 Variation of growth in height and weight of children. Il. After infancy. Acta Paediatr Scand 79:498-506

9. Heliövaara M, Aromaa A 1980 Height, Weight and Obesity of Finnish Adults [in Finnish]. Publications of the Social Insurance Institution ML:19, Helsinki, p 126

10. Kantero RL, Tiisala R 1971 Growth of head circumference from birth to 10 years. Acta Paediatr Scand [Suppl] 220:27-32

11. Karlberg J, Fryer JG, Engström I, Karlberg P 1987 Analysis of linear growth using a mathematical model. II. From 3 to 21 years of age. Acta Paediatr using a mathematical model

12. Prader A, Largo RH, Molinari L, Issler C 1989 Physical growth of Swiss children from birth to 20 years of age. Helv Paediatr Acta [Suppl] 52:1-125

13. Watson EH, Lowry GH 1962 Growth and Development of Children. Year Book Medical Publishers, Chicago
14. Tanner JM 1962 Growth at Adolescence. Blackwell Scientific Publications, Oxford, UK, pp 28-39

15. Siggers DC, Burke JB, Morris B, Normand ICS, Tanner JM, Williamson DAJ 1977 Cartilage hair hypoplasia. Postgrad Med J 53:473-478

16. Horton WA, Rotter JI, Rimoin DL, Scott CI, Hall JG 1978 Standard growth curves for achondroplasia. J Pediatr 93:435-438

17. Horton WA, Hall JG, Scott CI, Pyeritz RE, Rimoin DL 1982 Growth curves for height for diastrophic dysplasia, spondyloepiphyseal dysplasia congenita, and pseudoachrondroplasia. Am J Dis Child 136:316-319

18. Hecht JT, Hood OJ, Schwartz RJ, Hennessey JC, Bernhardt BA, Horton WA 1988 Obesity in achondroplasia. Am J Med Genet 31:597-602

19. Roede MJ, van Wieringen JC 1985 Growth diagrams 1980: Netherlands third nation-wide survey. Tijdschr Sociale Gezondheidzorg [Suppl] 63 